\title{
O princípio da partilha de saberes científicos vs. propriedade intelectual: a propósito das patentes farmacêuticas no contexto da pandemia de COVID-19
}

The principle of sharing scientific knowledge vs. intellectual property: Regarding pharmaceutical patents in the context of the COVID-19 pandemic

El principio de compartir conocimiento científico vs. propiedad intelectual: Respecto a las patentes farmacéuticas en el contexto de la pandemia COVID-19

Manuel Lopes Rocha ${ }^{1,2}$

\section{Resumo}

O direito de propriedade intelectual tem as suas exceções e os seus limites internos, previstos na lei. Nos últimos tempos, vem crescendo a discussão da sua compressão à luz de princípios gerais, como o interesse público, a liberdade de expressão ou a saúde pública. Dir-se-ia, pois, que estes direitos têm, também, uma função social, para além da proteção das prerrogativas dos seus titulares, o que é verdadeiro, sobretudo, para as patentes farmacêuticas. Grande parte desta discussão sempre passou, na verdade, pelas patentes farmacêuticas, sua concessão e exploração, em especial no que tange às patentes biotecnológicas. Esta discussão mais e mais se exacerbou quanto às patentes das vacinas destinadas ao tratamento contra a COVID-19. Não falta quem queira lançar mão dos meios previstos nas leis nacionais e internacionais para compelir às licenças obrigatórias das patentes e, até, à sua expropriação. Em causa, podem estar, no entanto, outros aspetos, como contratos mal negociados pela Comissão da União Europeia com algumas empresas farmacêuticas e os problemas logísticos na produção de vacinas. Por outro lado, centrar a discussão nas patentes poderá ser redutor, uma vez que há outros aspetos da propriedade intelectual a considerar. Contudo, a resposta estará, muito provavelmente, no equilíbrio entre os direitos dos titulares de patentes e o interesse público.

\section{Palavras-chave}

Propriedade Intelectual. Exclusivo. Limites. Patentes farmacêuticas.

\begin{abstract}
Intellectual property law has its exceptions and internal limits, as provided by law. In recent times, there has been a growing discussion of its compression in the light of general principles, such as public interest, freedom of expression or public health. It would be said,

\footnotetext{
${ }_{1}^{1}$ Advogado; membro da Direção Científica da revista Propriedades Intelectuais, Lisboa, Portugal; membro do Comité Editorial da revista Propriétés Intellectuelles, Paris, França. https://orcid.org/0000-0003-0393-1604. E-mail: mlopesrocha@outlook.pt

$2 \mathrm{O}$ autor destas linhas correu, conscientemente, um risco: o de escrever a quente sobre a atualidade. Por isso, muito do que se segue pode ser infirmado nos próximos tempos. No entanto, este é um tema que não começou com a epidemia de COVID-19 e continuará a discutir-se, estamos certos, muito depois desta epidemia estar mais controlada do que no presente. No momento em que escrevemos, começam a ser notícia os primeiros êxitos provenientes das campanhas de vacinação nos EUA ou em Israel. Ora, é justamente da prerrogativa do exclusivo, advinda do direito de patente, que trataremos em seguida. O pano de fundo é a intensa discussão pública sobre os seus limites neste contexto de pandemia, nomeadamente de escassez de doses de vacinas disponibilizadas no mercado. É o caso da União Europeia. Temos, por isso, consciência de que algumas das abordagens aqui referidas, podem ser desmentidas mais à frente. Todavia, o tema é tão aliciante e mesmo decisivo, que corremos o risco da oxidação rápida destas considerações. Tentaremos explicar, in fine, por que razão talvez tenha valido a pena esta opção. (Nota do Autor)
} 
therefore, that these rights also have a social function, in addition to protecting the rights of their holders, which is especially true for pharmaceutical patents. Much of this discussion has always, in fact, passed through pharmaceutical patents, their granting and exploitation, especially regarding biotechnological patents. This discussion has become increasingly exacerbated regarding the patents on vaccines intended for treatment against COVID-19. There is no shortage of people who want to use the means provided by national and international laws to compel mandatory patent licenses and even their expropriation. At issue, however, may be other aspects, such as contracts poorly negotiated by the European Union Commission with pharmaceutical companies and logistical problems in the production of vaccines. On the other hand, focusing the discussion on patents, can be reduced, there are other aspects of intellectual property to consider. However, the answer will most likely lie in the balance between the rights of patent holders and the public interest.

\section{Keywords}

Intellectual property. Exclusive. Limits. Pharmaceutical patents.

\section{Resumen}

La ley de propiedad intelectual tiene sus excepciones y límites internos, según lo establece la ley. En los últimos tiempos, ha habido un creciente debate sobre su compresión a la luz de principios generales, como el interés público, la libertad de expresión o la salud pública. Se diría, por tanto, que estos derechos también tienen una función social, además de proteger los derechos de sus titulares, lo que es especialmente cierto para las patentes farmacéuticas. Gran parte de esta discusión siempre ha pasado, de hecho, por las patentes farmacéuticas, su concesión y explotación, especialmente en lo que respecta a las patentes biotecnológicas. Esta discusión se ha exacerbado cada vez más con respecto a las patentes de vacunas destinadas al tratamiento contra COVID-19. No hay escasez de personas que quieran utilizar los medios que brindan las leyes nacionales e internacionales para imponer licencias de patentes obligatorias e incluso su expropiación. Sin embargo, pueden estar en juego otros aspectos, como los contratos mal negociados por la Comisión de la Unión Europea con algunas empresas farmacéuticas y los problemas logísticos en la producción de vacunas. Por otro lado, centrar la discusión en las patentes, se puede reducir, hay otros aspectos de la propiedad intelectual a considerar. Sin embargo, lo más probable es que la respuesta esté en el equilibrio entre los derechos de los titulares de patentes y el interés público.

\section{Palabras clave}

Propiedad intelectual. Exclusivo. Límites. Patentes farmacéuticas.

\section{Direitos de propriedade intelectual e limitações ao seu carácter exclusivo}

Entremos, sem mais delongas, no âmago do tema que aqui nos traz: os direitos de propriedade intelectual são, nos termos da lei, incluindo as convenções internacionais, monopólios, sem qualquer sentido pejorativo. Constituem, pois, direitos absolutos e exclusivos, girando, canonicamente, em torno da figura do criador ou do inventor. Bem se sabe que hoje já não é exatamente assim, mas este é, ainda, o ponto de partida, o vértice, sobre que são construídas as leis de propriedade intelectual. As leis seriam, assim, esferas delimitadas, contendo, todavia, alguns elementos de respiração ou de abertura, limitação e 
exceção, melhor dizendo. Essas esferas, agindo sobre si próprias, continham, e contêm, formas consagradas na lei que limitam, ou flexibilizam, essa prerrogativa de exclusivo típica, essencial, dos direitos de propriedade intelectual. Daí os pequenos catálogos de exceções e limites a tal exclusivo inseridos nas várias leis de propriedade intelectual. Ou seja, aqueles, bem delimitados casos em que alguém pode apropriar-se, em parte, da obra ou da invenção, sem que para tal necessite de autorização do titular do exclusivo. Em casos contados, tabelados, inscritos nas leis, o exclusivo é excecionado, o seu titular não se pode opor a essas utilizações livres. É assim no Direito de Autor, com um catálogo de exceções harmonizado numa diretiva da União Europeia. As exceções são, como se sabe, de interpretação restrita. Noutro plano, temos os limites dos direitos, como no caso das patentes, isto é, são áreas às quais, pura e simplesmente, não se pode estender este regime das patentes, o mesmo sucedendo no que respeita ao direito de autor, de resto.

Seja como for, as exceções são, ainda, elementos dessas esferas delimitadas, são exceções homónimas, fazem parte dessas leis, estão nelas inscritas num catálogo fechado, não podendo o intérprete permitir-se criar exceções ad hoc, quando lhe parece que, pela interpretação da lei, nela deveriam figurar, também. As exceções são aquelas e só aquelas que fazem parte da lei, não podendo ser objeto de interpretação extensiva ou analógica. São, repetimos, de interpretação restrita.

A questão que aqui nos traz é a da colocação, frontal, em causa, desta abordagem da lei. Ou seja, este sistema de esferas compactas, assente num exclusivo limitado por exceções internas, ou heterónimas, incrustadas no sistema de exclusivo, está em crise, como também está em crise o próprio modelo de direitos de patente, uma vez mais quanto ao seu exclusivo, de nada valendo ignorar este dado da realidade.

Não será este o local para discorrer sobre as causas de tal crise. E muitas são essas causas, algumas delas exibindo uma reação à extensão imperial, para usar uma curiosa expressão de Michel Vivant, dos direitos de propriedade intelectual (1). Se se procura agregar mais e mais realidades, na subsunção àqueles quadros legais, subsiste o risco de uma reação contrária. Este é um fenómeno conhecido do direito das patentes, como veremos infra, mas que está, neste momento, a replicar-se no âmbito do direito de autor.

Retomando o trilho da nossa exposição, cumpre constatar a emergência de exceções heterólogas no caso do direito de autor, isto é, exceções não previstas nos tais catálogos ou listas fechadas das leis, mas que acabam por impor-se, com inusitada força, na prática dos tribunais. Começam por ser tímidas iniciativas que batem à porta das tais esferas fechadas, 
reivindicando, aqui também, a flexibilização do exclusivo, e acabam por fazer o seu caminho, primeiro nos tribunais, até acabarem por forçar mesmo as portas da lei. Tratamos aqui, então, numa primeira fase, das exceções heterólogas ${ }^{3}$.

Ou seja, começam a pairar sobre os regimes legais estruturados de propriedade intelectual, valores, princípios, pairando acima desses enunciados normativos que, inevitavelmente, vão, como num efeito de plongé, bem conhecido da pintura, em que um efeito visual sugere uma queda, permeabilizar essas regras esféricas a que fomos aludindo. E é assim que, como vimos, o princípio da liberdade de expressão vai confrontar o direito de autor, tal como os valores da saúde pública vão questionar o exclusivo das patentes farmacêuticas, ou dos dispositivos médicos, muito mais em tempos de crise profunda como esta, a de uma epidemia mundial que ainda atravessamos.

Tudo isto não será assim para todas as realidades cingidas pelos direitos de propriedade intelectual. Esta tensão dialética não se põe da mesma forma quanto a todos os exclusivos de patente, como é óbvio. Existem milhões de patentes no mundo em que esta tensão não se verificará, como em domínios como a eletrónica ou a mecânica, por exemplo. Mas já não será assim em áreas de grande sensibilidade social como são as patentes farmacêuticas e os imperativos de defesa da saúde pública.

\section{A função social dos direitos de propriedade intelectual: o caso específico dos medicamentos}

Dir-se-á, então, que as prerrogativas de exclusivo, essência dos direitos de propriedade intelectual que, de certo modo, com eles se confundem, pois é a sua característica maior, conhecem uma limitação em nome de valores de saúde pública, como no caso das patentes farmacêuticas. Ou seja, se é verdade que os direitos de propriedade intelectual são objeto de um contrato social, como expresso no célebre preâmbulo da Constituição dos Estados Unidos da América, no sentido de que o monopólio que é concedido ao seu titular é provisório, teríamos aqui uma nova abordagem a esse contrato social $^{4}$. Com efeito, sabe-se que os founding fathers dos EUA deixaram bem claro que o exclusivo do direito era concedido, ao seu titular, como recompensa, permitindo-Ihe explorá-

\footnotetext{
${ }^{3}$ Sobre esta questão das exceções heterólogas e da limitação das prerrogativas de exclusivo, em direito de autor, por outros princípios, como o da liberdade de expressão, cfr. Gillian Davies (2); Strowel e Tulkens (3); o Acórdão do Tribunal de Justiça da União Europeia, tirado no Proc C-476/17, em 29 de julho de 2019 (Pelham) (4) e, ainda, o preâmbulo da Diretiva (EU) do Parlamento Europeu e do Conselho de 17 de abril de 2019, relativa aos direitos de autor e direitos conexos no mercado único digital (considerando 70) (5).

${ }^{4}$ Nesse sentido, cfr. Alexandra Abello (6, p.212ss).
} 
lo e dele receber proventos, sendo que tais direitos tinham um prazo de duração, permitindo que essa caducidade devolvesse tais direitos à comunidade. Mas, no nosso caso, o das formas de intervenção sobre o exclusivo das patentes farmacêuticas, o contrato social não significa um hope to see, um gozo sem limites durante um prazo limitado, findo o qual o exclusivo cessa e o direito é devolvido à sociedade. Na verdade, outra é a conceção que parece prevalecer, a do equilíbrio entre os direitos e a coletividade desde o início da vigência de tal direito. Tal conceito seria, pois, a forma essencial que subjaz à função social que os direitos de propriedade intelectual devem desempenhar. E sendo essa função social comum a todos os ramos desse amplo Direito, é justamente no escopo das patentes farmacêuticas que conhece a sua aplicação mais percuciente. ${ }^{5}$

Como referimos, a concessão de patentes é, em muitos casos, completamente indiferente ao cidadão comum. Afinal, na nossa vida quotidiana, quiçá sem o sabermos muito bem, somos, a cada momento, utilizadores intensos de produtos e processos patenteados. Mas, ao invés, a proteção, pela patente, de medicamentos, é um problema à volta do qual as discussões se eternizam. Não vale a pena ocultar: subsiste uma tensão grande, mesmo fora de um tempo urgente como o que atualmente vivemos, em que as patentes farmacêuticas são visadas. ${ }^{6}$ Afinal, a patente de medicamentos é recente, é uma novidade em relação ao direito das patentes, data de poucas décadas ${ }^{7}$. Por outro lado, é verdade, como lucidamente observa Michel Vivant (1), que estas questões decorrem de outros focos de tensão advindos de uma expansão enorme do objeto do direito das patentes e de uma não menor expansão geográfica num mundo que, se bem que alinhado na matriz que o Acordo TRIPS (10) representa, é, como veremos, um mundo profundamente desigual. Como sublinha este autor, não é a mesma coisa uma patente concedida e procurada em países como aqueles que integram a União Europeia e os EUA, e uma patente em países africanos de grande pobreza. As grandes empresas farmacêuticas estão sempre sob intenso escrutínio $^{8}$. São, também, correntes as críticas a práticas de evergreening (7) e daí que tenham sobrevindo tensões envolvendo as patentes e a sua exploração, em casos como o recuo da empresa Sanofi em prosseguir a exploração de uma molécula antiga numa nova

\footnotetext{
${ }^{5}$ Sobre este tópico, cfr. Elisabeth Berthet (7, p.25ss).

${ }^{6}$ Sobre este tema, a literatura é incomensurável. Ver, contudo, Hanns Ulrich (8, p.241).

${ }^{7}$ As patentes dos produtos químicos só foram admitidas sem restrição em 1976 no Japão, em 1978, na Alemanha, Dinamarca, Noruega, Suécia, Suíça, em 1980 na Finlândia. Para uma história da evolução da indústria farmacêutica em ligação à propriedade intelectual, cfr. Joseph M. Gabriel (9).

8 Para uma análise do comportamento das empresas farmacêuticas, ainda que sob uma perspetiva algo sensacionalista, cfr. Mikkel Borch-Jacobsen (11).
} 
combinação terapêutica no combate à tuberculose latente em 4 de agosto de 2020, sob pressão de uma organização não-governamental (12).

Daí que Vivant (1) problematize as críticas ao modelo da patente nos seguintes pontos:

- a patente já não é a recompensa que deveria ser;

- a patente já não é uma recompensa oferecida para uma invenção;

- a patente já não incita à divulgação;

- fora das suas terras de eleição (Europa, EUA) não incitaria ao investimento.

Veremos, na secção sobre o Acordo TRIPS, como o autor tempera esta abordagem crítica.

\section{Patentes e epidemias}

Mas essa era uma situação, ainda que controversa, bem diferente da situação atual que vivemos: uma pandemia universal em que, numa vitória prodigiosa da Ciência, em menos de um ano dispomos já de vacinas no mercado. E a pergunta que deve ter resposta sistematizada, é esta: se é verdade que as leis preveem uma intervenção estadual na exploração de patentes farmacêuticas, de que modo se deve configurar este tipo de intervenção neste tempo que vivemos? Que instrumentos existem nas leis, ou nos acordos internacionais que, num caso como o da pandemia da COVID-19, permitam ao Estado, em sentido lato, intervir na exploração de medicamentos protegidos por patente, pela invocação de princípios de saúde pública, aptos a comprimir o exclusivo? ${ }^{9}$

Desde logo, a emergência da pandemia trouxe, em sede de resposta organizada, a promoção de uma ética de partilha global, com iniciativas de partilha de resultados de investigação. Do mesmo modo, trouxe a criação de leis nacionais especificamente destinadas a combater a pandemia, com referências explícitas aos direitos de propriedade intelectual e possibilidades de determinar a emissão de licenças obrigatórias de exploração de patente. São os casos da França, da Alemanha e do Canadá, entre outros ${ }^{10}$.

No domínio da ética de partilha, cumpre assinalar que, já em maio de 2020, a Organização Mundial de Saúde advogava igual acesso a tecnologias destinadas a combater

\footnotetext{
${ }^{9}$ Sobre esta matéria, cfr. dois estudos incontornáveis: J.P. Remédio Marques (13, p.121ss) e Vítor Palmela Fidalgo (14, p.823ss).

${ }^{10}$ Para mais informação sobre este tópico da ética da partilha global e do movimento legislativo ad hoc, à escala mundial cfr. Vítor Palmela Fidalgo (14) e a excelente súmula publicada no número da revista online Lexology (15).
} 
a COVID-19, através da implantação de uma Technology Access Pool (C-TAP) que incluía previsões sobre patent pooling.

Outra iniciativa de relevo é a COVAX, criada em julho de 2020, destinada a distribuir 2 biliões de doses de vacinas em países em vias de desenvolvimento até final de 2021. A COVAX, presidida por José Manuel Durão Barroso, não parece debruçar-se sobre questões de propriedade intelectual Trata-se, afinal, de um mecanismo de financiamento para incentivar o fabrico de tecnologia para no combate à COVID-19 em larga escala.

Contudo, a principal figura emergente nesta indagação é a da licença obrigatória, a qual, como afirma certeiramente Vítor Palmela Fidalgo (16, p.59ss), é uma questão mediatizada. E se sempre foi, é, no presente, ainda mais discutida, ocupando mesmo o proscénio na discussão mundial dos direitos das patentes farmacêuticas. Em Portugal, como em muitos outros ordenamentos jurídicos, está prevista na nossa lei. Trata-se do art. $^{\circ} 111^{\circ}$ do nosso Código da Propriedade Industrial (CPI) (17) (aprovado pelo Decreto-Lei $\mathrm{n}^{\circ}$ 110/2018, de 10 de dezembro) cujo $n^{\circ} 1$ é lapidar para o tema que aqui cingiremos: o titular de uma patente pode ser obrigado a conceder licença para a exploração da respetiva invenção por motivo de interesse público.

Como supra referimos, aqui temos o princípio do interesse público como vetor externo que comprime o gozo ilimitado de um direito de exclusivo.

$\mathrm{E}$ o n. ${ }^{\circ} 2$ mais densifica que aspetos do interesse público devemos considerar. Para além do elemento da defesa nacional que aqui não nos importa, temos a saúde pública.

O n. ${ }^{\circ} 3$ também acrescenta outros tópicos que podemos transpor para o escopo que escolhemos:

Considera-se, igualmente, que existem motivos de interesse público quando a falta de exploração ou a insuficiência em qualidade ou quantidade da exploração realizada implicar grave prejuízo para o desenvolvimento económico ou tecnológico do País (17).

Poderemos sempre subsumir no princípio da defesa do interesse público, desdobrado na proteção da saúde pública, uma situação de exploração insuficiente em qualidade ou quantidade da patente em causa, como motivo da intervenção, quiçá suplementar, do Estado.

Para além das medidas nacionais, também a União Europeia prevê licenças obrigatórias para fins de fabrico e exportação de medicamentos para países com graves problemas de saúde pública, ao abrigo do Regulamento (CE) n 816/2006, do Parlamento 
Europeu e do Conselho (18), relativo à concessão obrigatória de patentes respeitantes ao fabrico de produtos farmacêuticos destinados à exportação para países com problemas de saúde pública.

Convém, no entanto, ter presente que o regime de emissão de licenças obrigatórias de direitos de patente, por motivos de interesse público, deve ser apenas usado in extremis se e quando outras medidas menos intrusivas não forem aplicáveis no caso concreto.

\section{O Acordo TRIPS e a Declaração de Doha}

Na secção antecedente aludimos a princípios e limitações aos direitos de propriedade intelectual, vazados na nossa lei (CPI), sejam essas limitações advindas de interesses privados ou do interesse público, como no $\operatorname{art}^{\circ} 111^{\circ}$ do $\mathrm{CPI}$ (17) e num Regulamento da UE (18). Mas estas são soluções portuguesas regionais, restando aqui saber se, para além destas, subsistem regras inscritas em instrumentos de direito internacional que se apliquem numa grande maioria de Estados contratantes.

A este respeito, temos constatado, no tema que aqui abordamos, a incessante referência ao Acordo TRIPS (10) e à Declaração de Doha (19). Vejamos, muito sumariamente, como estes instrumentos internacionais abordam a questão da limitação do direito de patentes. $O$ artigo $8^{\circ}$ do Acordo TRIPS (10) habilita os Estados a recorrer a medidas apropriadas para lutar contra a utilização abusiva dos direitos de propriedade intelectual, ou as práticas restritivas nesta área. Este artigo permite, assim, proteger a saúde pública e a nutrição. Em caso de urgência sanitária, ou quando o titular de direitos sobre uma patente vende os seus medicamentos em quantidade insuficiente ou a um preço demasiado elevado, os países membros são autorizados a acordar com um terceiro, contra uma remuneração adequada, tendo em conta o valor económico da autorização, e mediante certas condições, uma licença obrigatória para o titular do direito.

Entretanto, em 2001, aquando da $4^{\text {a }}$ Conferência Ministerial da Organização Mundial de Comércio (OMC), foi aprovada uma declaração que constituiu um progresso no debate entre os direitos privativos de propriedade industrial e o acesso à saúde pública, mais precisamente uma contenda que nasceu devido aos elevados preços dos medicamentos patenteados, que impediam os países menos desenvolvidos e alguns países em desenvolvimento de aceder aos mesmos e auxiliar a sua população a braços com epidemias.

Dessa Conferência Ministerial saiu a denominada Declaração de Doha (19) sobre o Acordo TRIPS (10) e a Saúde Pública. Nesta Declaração, composta por sete pontos, o 
grande passo estaria contido no seu parágrafo $6^{\circ}$ que reconhecia que os membros da OMC com capacidades insuficientes ou mesmo inexistentes para fabricar medicamentos, poderiam ter dificuldades na utilização de licenças compulsórias nos termos do Acordo TRIPS. Por isso, em 30 de agosto de 2003, o Conselho do TRIPS chegou a uma solução, acordando que o mencionado parágrafo 6 da Declaração de Doha (19), deveria ser aplicado, derrogando-se parcialmente a alínea f) do art. ${ }^{\circ} 31^{\circ}$. Com essa decisão, os membros da Organização Mundial de Comércio passaram a dispor de um instrumento com uma grande força jurídica que lhes permitia proceder à importação e exportação de produtos farmacêuticos, de modo a suprir as necessidades de saúde pública ${ }^{11,12}$.

\section{Levantar, abrir e quebrar patentes}

Ora, é neste contexto que se vai inserir o último ponto que abordaremos e que constitui o âmago da nossa abordagem. Como decorre do título, analisaremos uma parte do debate público de que a Comunicação Social, e não só, se tem feito eco, sobre as consequências do atraso na vacinação nos Estados que integram a União Europeia. Tais atrasos resultariam do incumprimento, na remessa das doses de vacinas acordadas, principalmente, por uma empresa anglo-sueca, a AstraZeneca. No momento em que escrevemos, a AstraZeneca enfrenta outro problema que é a suspensão da utilização da sua vacina em alguns Estados europeus, entretanto já levantada depois de eliminadas as dúvidas quanto à sua idoneidade, pela Agência Europeia do Medicamento.

Como é evidente, vamo-nos socorrer nesta exposição de muitas notícias, reproduzindo determinadas posições tomadas, também, por líderes políticos portugueses, sendo certo que este é um debate mundializado, não é exclusivo do nosso país. Abordaremos, também, outras declarações e artigos publicados, principalmente, nos órgãos nacionais portugueses. Poderá contestar-se a bondade desta recolha e da importância que Ihe é dada. Afinal, trata-se de posições conjunturais, voláteis, peças jornalísticas destinadas ao esquecimento, passadas poucas horas da sua publicação. Discordamos, totalmente, de tal opinião. Quase todas estas posições convergem num ponto de vista de crítica frontal à atuação das instituições portuguesas e da União Europeia, o que, já de si, seria importante, mas insistindo na necessidade ingente de se levantar, abrir e, de forma mais contundente,

\footnotetext{
11 Sobre esta temática, seguimos de muito perto, Vítor Palmela Fidalgo (16). Cfr., também, a excelente súmula disponibilizada na Lexology (15).

12 Para além das obras já citadas, de muito interesse para a análise do Acordo TRIPS, propriedade intelectual e medicamentos, cfr. Bernard Remiche e Jorge Kors (20) e Carlos M. Correa e Sandra C. Negro (21).
} 
quebrar as patentes farmacêuticas. Ou seja, não se trata de criticar uma determinada conduta, no caso da União Europeia, vai-se mais longe e pretende-se mesmo a tomada de medidas drásticas que, fatalmente, vão ter consequências para as patentes farmacêuticas, para os seus titulares e para o próprio direito das patentes como o conhecemos hoje. E não se diga que este feixe de opiniões convergentes não tem a importância que lhe emprestamos. Tem, e muita, pois é este caldo de cultura, este tópico incessantemente discutido e repercutido, aceite por vários quadrantes, que influencia o decisor político e o Estado-legislador.

Assim, num artigo publicado no jornal Público em 7 de fevereiro de 2021 (22), o eurodeputado João Gusmão e outros ${ }^{13}$ fazem uma radiografia das dificuldades da Comissão da União Europeia em garantir o número de doses de vacinas suficientes para os cidadãos dos Estados que integram a UE. Aludindo aos apoios de que as empresas envolvidas na criação de vacinas beneficiaram, apelam a que as vacinas sejam consideradas um bem público mundial, e chamam a atenção para as dificuldades que a Comissão da UE teria num litígio judicial com as empresas farmacêuticas produtoras destas vacinas, entre outros pontos de muito interesse acresce a comodidade de links para outras fontes de informação. No que ora nos move, fazem uma alusão à Declaração de Doha (19) e rematam desta forma:

Ou as farmacêuticas libertam as patentes a preços razoáveis, ou essas patentes terão de ser quebradas e divulgadas livremente. A capacidade produtiva existente deve ser plenamente utilizada e alargada, na medida do possível. Já morreram mais de dois milhões de pessoas por causa da covid, fora as que não entram nas estatísticas. Essas vidas valem mais do que os lucros de um negócio pago por nós. (22)

Também num artigo publicado no jornal Expresso, de 12 de fevereiro de 2021, José Soeiro faz uma abordagem muito semelhante, ainda que mais sucinta, à dos autores do artigo do jornal Público, afirmando a dado passo:

Por isso, ou as farmacêuticas libertam as patentes por um preço razoável, ou então estas deveriam ser quebradas, como aconteceu já por várias vezes neste século, nomeadamente pelos EUA. (23)

Ainda no jornal Público, Miguel Prata Roque publicou dois artigos muito críticos da conduta da Comissão Europeia e, também, do Presidente da República Portuguesa:

E o que é que fez o decreto presidencial de emergência quanto a isso? Nada.

13 José Gusmão, Moisés Ferreira e Bruno Maia. 
Não determinou qualquer comando normativo de suspensão temporária dos direitos de patentes (isto é, de propriedade privada), com vista a garantir que outras empresas farmacêuticas - em especial, a indústria dos medicamentos genéricos - iniciem, de imediato, a produção em massa de vacinas. (24)

Neste último caso, ao contrário dos anteriores que se quedam por recomendações genéricas, deve realçar-se que o autor preconizaria a inserção, no decreto presidencial que decretou o estado de emergência, no contexto da pandemia, de clausulado concreto de suspensão temporária dos direitos de patentes aqui em causa.

Num artigo publicado em 25 de fevereiro, no jornal Expresso, José Gusmão (25) rebate um outro artigo publicado por Catarina Maia (26), em 16 de fevereiro no mesmo jornal, em que a autora defendeu a ideia de que as atuais dificuldades têm menos que ver com abusos de titulares de patentes, e mais com problemas no fabrico de doses suficientes de vacinas, os quais classificaríamos de logísticos. Quanto ao que releva para estas nossas breves linhas, José Gusmão remata:

O levantamento de patentes e a atribuição de licenças compulsórias não só não é ilegal à luz do direito internacional, como é um poderoso instrumento de saúde pública que deve ser utilizado em situações de necessidade, por via da vontade politica e da legislação interna nos países (como previsto no objetivo 3 dos Objetivos de Desenvolvimento Sustentável da Agenda 2030 da ONU). Prova que assim é já foi dada nesta crise de várias formas. 1) Vários países, logo no início da crise pandémica, reforçaram a sua legislação interna para a emissão compulsória de licenças, caso fosse necessário quebrarem patentes em medicamentos e vacinas. 2) A secção 104 e 105 da Lei das Patentes de Israel, acionada pelo Ministro da Saúde a favor do Departamento de Emergência do seu Ministério da Saúde, a 23 de março de 2020, para emitir uma licença compulsória da importação do antirretroviral Kaletra para o tratamento de pacientes covid-19. 3) Os EUA, num contexto em que não era garantido o sucesso de vacinas a que os EUA tivessem acesso de forma fácil, prometeu acionar licenças para obter vacinas de qualquer forma. (25, grifo nosso)

Aqui, este autor já concretiza mais em relação a tomadas de posição anteriores e equipara levantamento de patentes a atribuição de licenças compulsórias, não esquecendo, noutro ponto daquele artigo, que tal situação implicaria a compensação razoável aos titulares dessas patentes.

Num artigo publicado no jornal Expresso em 26 de fevereiro de 2021, Inês Monteiro Alves interroga-se sobre a utilização da figura das licenças obrigatórias no contexto do Acordo TRIPS (10), tendo presente a pandemia que atravessamos:

Será o mecanismo das licenças compulsórias, ainda assim, suficiente, para o combate à pandemia de covid-19? Ainda que o acordo TRIPS preveja a 


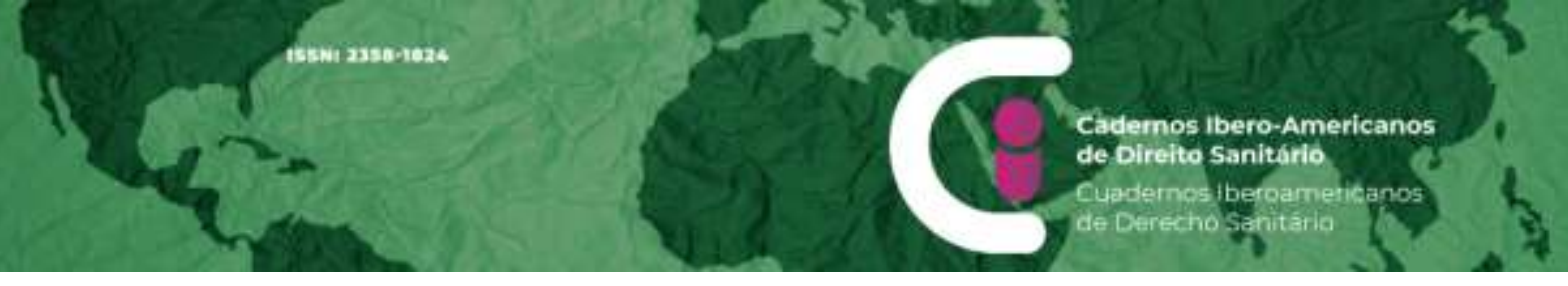

faculdade de atribuição de licenças compulsórias (suspensão temporária do direito de exclusividade do titular de uma patente, permitindo a produção, uso, venda ou importação do produto patenteado, por um terceiro), certo é que estas são atribuídas caso a caso, atrasando o processo de escalada de produção industrial, um processo que se quer, neste momento, muito célere. (27)

Finalmente, num artigo publicado no jornal Público, de 12 de março de 2021, Pedro Filipe Soares faz alusões a uma eventual conduta dos Estados no que tange ao exclusivo das patentes, mas sem concretizar em procedimentos determinados:

Já percebemos que a partilha da tecnologia das farmacêuticas não está nas suas intenções. As patentes são a garantia do monopólio e o lucro não pode ser colocado em causa, nem que seja por uma pandemia. No entanto, o investimento para o desenvolvimento e a testagem das vacinas foi feito sem risco para estas multinacionais. Houve muito investimento público e uma garantia de compra qualquer que fosse a eficácia das vacinas. Os cidadãos pagam, mas não mandam. Mas não tem de ser assim. Ao contrário do que dizem, a legislação sobre a propriedade industrial não deixa os Estados de mãos atadas. Há mais de cem anos que situações como esta que enfrentamos, de catástrofe, serviram para introduzir nesta legislação figuras jurídicas como a licença obrigatória em casos em que esteja em causa o interesse público ou seja de importância para a Saúde Pública. Haja vontade política, não estamos condenados a esta escassez de vacinas. (28)

No plano de tomadas de posição de líderes de partidos políticos, assinalemos a posição pública de Catarina Martins, do Bloco de Esquerda (BE), que afirmou em 13 de março de 2021, numa entrevista à Rádio Observador:

Este era o momento da UE utilizar os mecanismos que tem, legislativos, nomeadamente, as licenças compulsórias, para ultrapassar as patentes e generalizar a produção da vacina. (29, grifo nosso)

Esta posição do Bloco de Esquerda está, também, reafirmada na edição do Jornal de Negócios de 1 de fevereiro de 2021 (30).

Por fim, Jerónimo de Sousa, Secretário-Geral do Partido Comunista Português (PCP), em declarações públicas em Alhandra, em 14 de março de 2021, afirmou:

Somos ligeiros a confinar e pouco ágeis a obter e comprar as vacinas necessárias. Desconfinamos a conta-gotas porque estamos a fazer uma vacinação a conta-gotas. Nem a UE nem o Governo estão dispostos a comprar vacinas fora dos fornecimentos dos laboratórios das grandes farmacêuticas americanas e europeias, nem a fazer pressão para se libertarem patentes e licenças, como recomendou a Organização Mundial de Saúde (OMS). (31) 
Curiosamente, também em França, o secretário nacional do Partido Comunista francês, Fabien Roussel ${ }^{14}$, se pronunciou nesse sentido: "Le sujet est trop grave pour laisser les brevets aux mains d'intérêts privés.»

Ao que parece, também preconizou a requisição das fábricas aptas a produzir vacinas, de resto como Miguel Prata Roque (24).

Do mesmo modo, a ex-eurodeputada Ana Gomes (33), num tuíte datado de 13 de março, afirmou que nada é agora mais vital para a Humanidade, acusando a UE de inação, mencionando mesmo Ursula Von der Leyen e António Costa, concluindo com um apelo: "Abram patentes, Já! a vacina não é um produto de mercado, é Bem Público Universal! Salvem VIDAS!"

Numa declaração ao jornal Expresso, de 3 de março de 2021, sob o título Farmacêuticas devem preocupar-se mais em acabar a pandemia do que ganhar mais dinheiro, Durão Barroso afirmou sobre uma pergunta relativa ao levantamento de patentes, considerando-a um desafio muito difícil:

Além, obviamente, da grande divergência entre os interesses em jogo, [a abertura da propriedade intelectual para vacinas] não leva em consideração a complexidade do seu desenvolvimento científico e tecnológico, que geralmente envolve milhares de etapas e um grande 'know-how'", o que as torna diferentes dos medicamentos que podem ser fabricados por produtores de genéricos, argumenta.

É um processo que vai bem além do mandato da GAVI e cuja resolução estaria dependente dos governos do mundo, "o que já foi por vezes tentado no âmbito da Organização Mundial do Comércio, mas sempre sem nenhum resultado concreto. (34)

Tendo presente este acervo de artigos, declarações e tomadas de posição públicas sobre o tema das patentes em tempo de pandemia de COVID-19, é-nos lícito afirmar que algumas destas posições estão eivadas de um certo simplismo, o que não significa, como veremos, que não mereçam resposta e ponderação. Compreende-se que a linguagem dos media não se compadeça com análises muito profundas e detalhadas, mas, na generalidade, deparamos com menor cuidado nas tomadas de posição referidas, com exceção das bem documentadas análises de José Gusmão (25), Catarina Maia (26) e Inês Monteiro Alves (27), que fornecem, ainda assim, não só interessantes argumentos, como pistas de análise e cuidado na argumentação.

\footnotetext{
${ }^{14}$ Citado por Jean-Michel Bazat (32).
} 
Há, no entanto, alguns pontos que cumpre sublinhar nesta discussão. Alude-se muito a licenças obrigatórias ou compulsórias de patente, a própria lei portuguesa, como vimos, também o permite (artigo $111^{\circ}$ do CPI) (17). Mas como, certeiramente, lembra Remédio Marques:

Nas eventualidades de pandemias ou epidemias nascentes para as quais ainda não haja patentes já concedidas, torna-se difícil ou impossível, na prática, mobilizar o regime das licenças obrigatórias - exceto se outros medicamentos já aprovados e objeto de direitos de patente ou CCP puderem ser usados para essa nova indicação terapêutica. As vacinas ou retrovirais verdadeiramente inovadores e ainda não sujeitos a procedimentos de aprovação sanitária provavelmente não são objeto de direito de patente (ou $\mathrm{CCP}$ ) no momento em que os Governos mais necessitam ou equacionam a utilização da figura jurídica das licenças compulsórias. ${ }^{15}(13)$

Ora, conviria, em primeiro lugar, assentar de que patentes aqui tratamos. Enquanto não se souber, de ciência certa, quais as patentes sobre as quais se vai exercer o mecanismo, excecional, da licença obrigatória, como é possível estar a apelar, constantemente, para que seja desencadeado? Veja-se que só a empresa MODERNA tem cerca de doze patentes no que tange ao SARS-CoV-2. Por outro lado, as patentes não pertencem apenas a empresas privadas. Neste domínio, também o U.S. National Institute of Health $(\mathrm{NIH})$ é titular de patentes relevantes para estas vacinas, bem como o próprio Governo dos EUA. E saberíamos, então, quais as exatas patentes que são necessárias para o subsequente fabrico de vacinas cujas patentes seriam objeto de licenças obrigatórias? ${ }^{16}$

A própria Pfizer tem dificuldades quanto aos pedidos de patente para esta vacina contra a COVID-19. Por outro lado, quem pretender usar as suas invenções nesta área não verá a mesma abertura demonstrada pela MODERNA, que afirmou não deduzir qualquer procedimento contra quem usar as suas patentes, sem autorização, neste quadro de pandemia. Considerando, o complexo de tecnologias que estão na base da vacina da Pfizer, as licenças obrigatórias poderiam ter de se distribuir por várias patentes. (37)

Num outro plano, será dificilmente concebível que a invenção subjacente às várias vacinas disponíveis no mercado, obedeça apenas à lógica da patente, isto é, dependerá de outros conhecimentos que não foram, ou não podem mesmo ser patenteados. Estariam aqui em causa segredos industriais ou know-how, como a própria MODERNA admite (36), pelo que estar sempre a apelar à intervenção sobre as patentes pode ser redutor. Do mesmo

\footnotetext{
${ }^{15}$ Como é evidente, Remédio Marques (13) discute outras alternativas, de jure condendo, à proteção pela patente, tema que aqui não desenvolveremos. No mesmo sentido, cfr. Dário Moura Vicente (35, p.7 ss)

16 Sobre este tema, cfr. Mario Gaviria e Burucu Kilic (36).
} 
modo, como conclui, uma vez mais, de forma certeira, Remédio Marques, nos termos que agora mesmo evidenciámos, uma vacina

pode achar-se protegida por vários direitos de patente (v.g. das substâncias intermediárias, dos materiais de partida, do (os) processo (s) de síntese química ou biotecnológica, da formulação farmacêutica, etc.), os quais, por força da observância do princípio da unidade da invenção (art $73^{\circ}$ do $\mathrm{CPI}$ ), foram objeto de vários pedidos ou de pedidos divisionários. (13)

Ainda nesta análise, deve ponderar-se que as vacinas da MODERNA e da Pfizer são tributárias da tecnologia ARN mensageiro. Para realizar uma vacina, os investigadores fabricam, habitualmente, um antigene que apresentam ao sistema imunitário a fim de que este produza anticorpos adaptados. Mas diferentes métodos são possíveis: utilizar o vírus inteiro, inativo ou atenuado, usar um fragmento, ou combiná-lo com um vírus já bem controlado. Este novo, e revolucionário, método deixa que as células façam o seu trabalho, ou seja, trata-se de injetar no organismo não o antigene, mas o seu modo de uso, o seu código genético, sob a forma de RNA (ácido ribonucleico) ${ }^{17}$.

Deve referir-se que as duas empresas que já disponibilizaram esta vacina no mercado, MODERNA e BioNtech, se bem que esta sob acordo com a Pfizer, são pequenas empresas, startups, MODERNA é o acrónimo de Modified RNA.

Em janeiro de 2020, só havia duas empresas de biotecnologia capazes de responder, imediatamente, aos desafios de uma vacina baseada na tecnologia ARN mensageiro, precisamente a BioNTech e a MODERNA, e, eventualmente, com maior atraso, a Cure VAC. $(40$, p. 54ss)

Além disso, se esta invenção serviu para obter, rapidamente, vacinas $A R N$, foi porque está baseada em décadas de investigação num dos mais fundamentais aspetos da vida na Terra: como são os genes transcritos no ARN que dizem às células quais as proteínas que deve juntar. (39, p. 26)

No que tange aos direitos de propriedade industrial que resultaram da investigação em ARN, liderada por Drew Weisman e Katalin Kariko, estes trabalhos deram origem a uma invenção patenteada em nome da Universidade da Pensilvânia, embora estes dois investigadores nela figurem como inventores. Tratava-se da molécula sintética de ARN mensageiro que podia ser inserida nas células humanas sem atacar o sistema imunitário do corpo humano. Já a MODERNA não dispunha de qualquer patente sobre a tecnologia

\footnotetext{
${ }^{17}$ Alude a esta tecnologia ARN mensageiro, Luís Archer no relato que faz da sua vida de cientista, Vinte e cinco anos de Genética Molecular (38). Cfr., ainda, o excelente dossier sobre este tema de Walter Isaacson (39).
} 
concebida na Universidade da Pensilvânia para fabricar um ARN mensageiro inofensivo para o organismo. Por isso, esta empresa pagou por uma licença dessa tecnologia de 75 milhões de dólares, sendo que também a BioNTech pagou uma licença para explorar o ARN modificado inventado por Katalin Kariko (41).

Sabe-se que em 2010, Weisman e Kariko tentaram (re)adquirir a patente à sua Universidade, mas foram ultrapassados pela empresa de biotecnologia Epicentre, hoje CELLSCRIPT ${ }^{18}$.

Noutro plano, a AstraZeneca, já tinha feito, em 2013, um acordo com a MODERNA, no valor de 240 milhões de dólares para desenvolver diferentes terapias com base no ARN mensageiro. Mas faltava a patente cuja licença, como vimos, a mesma MODERNA pagou à Universidade da Pensilvânia. Convém referir que, no acordo assinado com a Pfizer, a BioNTech reservou para si o exclusivo do produto.

O que esta saga impressionante das empresas que desenvolverem o ARN mensageiro ilustra bem é, como dissemos, a importância das empresas de biotecnologia, no caso duas pequenas startups e a vitória, para já, deste tipo de vacinas ${ }^{19}$. Mas basta ler a entrevista da investigadora Katalin Kariko para concluir que nada disto foi fácil porque tiveram de se bater contra a desconfiança das grandes empresas farmacêuticas e com problemas de financiamento da sua investigação. Aqui avulta, o importantíssimo papel desempenhado, desde o início, por Anthony Fauci e as quantias em dinheiro que foi capaz de mobilizar para estas investigações nomeadamente através do seu U.S. National Institute of Allergy and Infectious Diseases (NIAID)

No plano da partilha dos saberes, Kariko alude a um grande diálogo destas pequenas empresas (CureVAC, BioNTech e Moderna) com investigadores japoneses, coreanos e chineses, em encontros académicos desde 2013.

Mas, aqui chegados, não podemos deixar de nos interrogar com Jean-Michel Bazat (32) se transformar assim, tão rapidamente, estas inovações em genéricos não terá como risco a desmotivação dos investigadores, num momento em que exploram as vacinas para conter as mutações do vírus. E não será justo que aqueles pioneiros que assumiram o risco, muitas vezes contra as grandes farmacêuticas, de seguir a pista do ARN mensageiro, como a equipa da BioNTech, incluindo a sua atual VP Katalin Kariko, venham agora recolher os seus frutos?

\footnotetext{
${ }^{18}$ Katalin Kariko (42), em entrevista, confirma este facto.

19 Sobre patentes e biotecnologia, cfr. Philip W. Grubb. e Peter R. Thonsen (43).
} 


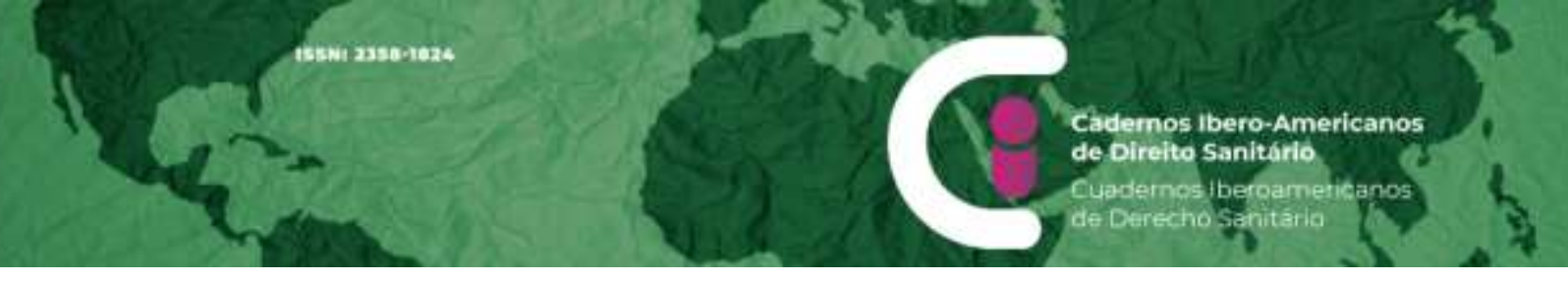

Por outro lado, a MODERNA assumiu publicamente, o seguinte compromisso:

\begin{abstract}
Beyond Moderna's vaccine, there are other COVID-19 vaccines in development that may use Moderna-patented technologies. We feel a special obligation under the current circumstances to use our resources to bring this pandemic to an end as quickly as possible. Accordingly, while the pandemic continues, Moderna will not enforce our COVID-19 related patents against those making vaccines intended to combat the pandemic. Further, to eliminate any perceived IP barriers to vaccine development during the pandemic period, upon request we are also willing to license our intellectual property for COVID19 vaccines to others for the post pandemic period. (44).
\end{abstract}

Em resposta ao artigo de Catarina Maia (26) publicado no Expresso, a que já aludimos, José Gusmão afirma o seguinte:

Como foi prontamente denunciado pelos Médicos sem Fronteiras, o compromisso da Moderna é totalmente vazio, se não for acompanhado da divulgação dos processos necessários à produção da vacina. A Moderna assume um compromisso que sabe ser inútil, como prova o facto de não ter aderido à plataforma de partilha da OMS. (25)

Mas, como resulta da declaração da MODERNA, esta está disposta a licenciar a sua propriedade intelectual. Ora, nenhuma empresa pode afirmar um licenciamento, escamoteando depois os dados essenciais para que o licenciado possa desenvolver o seu produto. Daí que o licenciamento da MODERNA deva incluir, naturalmente, todos os outros componentes necessários, sejam segredos industriais (know-how), seja toda e qualquer informação técnica necessária.

Também sobre a utilização do Acordo TRIPS (10), nesta sede, José Gusmão diz-nos o seguinte:

Catarina Maia diz que já em março de 2020 havia propostas para suspender o acordo TRIPS que regula a propriedade industrial no âmbito da OMC. Não refere que propostas eram essas. Mas o acordo em causa estabelece nos artigos 30 e 31 uma ampla margem de manobra para que os Estados possam impor exceções à proteção associada à propriedade industrial. A Declaração de Doha, também no âmbito da OMC (e do TRIPS) confirma e reforça essas exceções em contexto de crises de saúde pública. Em resumo, o acordo TRIPS não precisa de ser suspenso, pelo simples facto de já conter disposições mais do que suficientes para lidar com a atual situação. (25)

Mas há, aqui, certamente um equívoco, pois aquilo a que Catarina Maia se referia, certamente, é à proposta da África do Sul e da Índia para uma compressão dos direitos de propriedade industrial dos titulares das patentes, a fim de permitir um mais fácil acesso às 
vacinas da COVID-19. Ora, essa proposta foi rejeitada pelo Conselho do TRIPS em outubro de 2020 (45).

Cumpre assinalar, por outro lado, que do que se sabe no momento em que escrevemos, é que os problemas da União Europeia são com uma concreta empresa, a AstraZeneca. Se só esta tem criado problemas com o seu atraso no envio das doses de vacina acordadas, por que razão todas as outras empresas que têm cumprido os seus acordos, devem ver as suas patentes sujeitas a licenças obrigatórias? Seria justo este anátema sobre todas as empresas, mesmo as cumpridoras? Seria, então, uma espécie de sanção transversal, com efeito dominó: se uma é compelida a aceitar uma licença obrigatória da ou das suas patentes, as outras também serão.

E esta obrigação de licenciamento obrigatório valeria também para as vacinas russa (laboratório Gamaleya) e chinesas (laboratórios Sinopharm e Sinovac)?

Por outro lado, poderemos já concluir o debate sobre as condições logísticas necessárias para o fabrico em massa de vacinas? É ou não verdade que as condições de produção de algumas vacinas, pelos menos, são assaz complexas? Como se explica que empresas como a Sanofi só estejam em condições de começar a produzir as vacinas dos outros em agosto de 2021 ?

É que, por exemplo, no que tange à vacina da BioNTech/Pfizer a sua distribuição é algo extremamente delicado e complexo, obrigando a uma logística impressionante. Desde logo, porque esta vacina obriga a conservação a temperaturas de -70 graus e os seus frascos têm de ser fabricados por uma empresa alemã especializada, Schott, na produção de tais frascos utilizados por milhões nas investigações clínicas sobre o vírus. Acresce a logística do transporte, devendo ser garantida a existência de centros farmacêuticos nos aeroportos, como o da empresa Lufthansa Cargo no aeroporto de Frankfurt, onde estão localizados os super congeladores necessários, providenciados pela empresa alemã Binder, onde faz mais frio do que no Ártico (46).

Numa muito interessante entrevista dada pela diretora científica da Organização Mundial da Saúde, Soumya Swaminathan, a Clara Barata do jornal Público (edição de 7 de março de 2021), esta cientista e diplomata afirma:

O grande problema é que a quantidade de vacinas é limitada. Os produtores não conseguem fabricar mais. É pouco realista esperar que se conseguirá ter milhares de milhões de doses mais. O que é necessário é uma distribuição mais justa das vacinas, para proteger as populações vulneráveis. Julgo que na segunda metade deste ano teremos muito mais vacinas, e todos os países 
estarão mais bem abastecidos. O que se está a passar é que alguns países têm mais vacinas do que outros. Depois de vacinarem as suas populações prioritárias, eles vão partilhar, vão doar doses através da COVAX, para que outros países em África possam vacinar as suas populações prioritárias. (47)

Também a investigadora Teresa Summavielle, intervindo num seminário promovido pelos eurodeputados do Bloco de Esquerda, afirmou que o valor de investimento para que Portugal tivesse uma infraestrutura capaz de produzir 50 milhões de doses da vacina por ano está estimado em cerca de 100 milhões de euros, sendo necessários dois anos para que ficasse operacional (48).

E os investimentos das empresas farmacêuticas, que já vêm de há anos? É verdade o grande investimento público que José Gusmão (25) refere. Por exemplo, a BioNTech recebeu um empréstimo do Banco Europeu de Investimento e o inventor Ugur Sahin beneficiou de uma bolsa de excelência da UE. Já a MODERNA teve de pedir fundos ao governo norte-americano por não ter o músculo financeiro da Pfizer, tendo beneficiado do apoio do National Institute of Allergy and Infectious Diseases liderado, como referimos, por Anthony Fauci. Todavia, a Pfizer investiu nesta vacina a soma astronómica de 1,5 biliões de dólares, quando se sabe que a colocação de um medicamento novo no mercado custa, hoje em dia, à volta de 800 milhões de dólaes (1).

Tudo isto sem esquecer que o contraponto da maravilhosa vitória da Ciência no caso das vacinas ARN, é o falhanço de duas celebradas instituições francesas, a empresa Sanofi e o Instituto Pasteur. Muitos sublinharam a amarga ironia de o Instituto, que tem o nome do inventor da vacina contra a raiva, perder o pelotão da frente no desenvolvimento de vacinas contra a COVID-19. Na verdade, o Instituto Pasteur tinha um projeto com a empresa Merck, visando aquele objetivo. Trata-se ao que parece, também, de uma história de rivalidades científicas, algo que acontece muito nestas competições humanas. A verdade é que o chefe da unidade de inovação em vacinas, daquele Instituto, patenteou em 2004 uma vacina eficaz contra o Sars-CoV-1. Por outro lado, o Instituto consagrou um quarto dos seus efetivos e mais de metade dos seus laboratórios a um projeto para conseguir, em tempo record, uma vacina, tendo este projeto o nome de código V591 (49).

No que respeita à Sanofi, o L'Express não hesitou em puxar o tema para capa, Sanofi, un fiasco français. Trata-se de um impressionante dossier no qual se enumeram os sucessivos falhanços deste gigante farmacêutico que, pelo seu atraso na corrida à vacina anti-COVID-19, está hoje remetido a uma situação de subcontratado, para a produção de vacinas, pelo seu principal concorrente Pfizer-BioNTech (50). 
Muitas são as causas enumeradas que explicam este falhanço da Sanofi, desde o seu atraso no diálogo com as empresas de biotecnologia, as grandes vencedoras desta corrida, ao lançamento tardio das alianças quanto ao ARN mensageiro, entre outras. Mas uma das mais interessantes razões para o que o L'Express designe de fiasco é a falaise des brevets. Na verdade, as patentes têm um prazo de caducidade de vinte anos e as patentes mais importantes da Sanofi começaram a cair no domínio público. Para tanto, a Sanofi deveria ter dedicado mais meios a investir, descobrir, inventar, o que não terá sucedido e, em grande medida, tal explica o atraso que esta empresa agora conhece.

Tudo isto para sublinhar que a evolução nestas áreas não é linear, há avanços, recuos, há falhas, há investimentos perdidos.

E como é que, na prática, se decidiriam as licenças obrigatórias? Seria cada Estado por si? Os Estados afastariam a União Europeia do processo, sendo certo que é esta quem tem negociado em seu nome as vacinas com quem as produz? Como se assumiriam responsabilidades por roturas contratuais? E mesmo no quadro da OMC, recorrendo ao Acordo TRIPS, como se procederia? Quem tomaria a iniciativa? Como assinala Inês Monteiro Alves (27), tem-se em conta a demora que um processo destes pode importar? Basta atentar nas experiências anteriores, sem esquecer a já referida, de outubro de 2020, pela recusa da proposta da Índia e da África do Sul.

Será também viável uma iniciativa como a que Miguel Prata Roque (24) pretende, a suspensão unilateral, por Portugal, de direitos de patente, através de decreto presidencial? Num mundo multilateral, em que somos membros de organizações internacionais, terá essa via alguma viabilidade? Ponderaram-se as consequências, desde logo as indemnizações a pagar, para Portugal, caso avançasse, sozinho, para uma decisão dessas?

Finalmente, há uma questão subjacente a esta discussão que vai para além das licenças obrigatórias e dos eufemismos dos levantamentos, aberturas e quebras de patentes, isto é, a possibilidade extrema da expropriação por utilidade pública das mesmas patentes, como refere Remédio Marques (13). E também aqui a nossa lei o permite (art ${ }^{\circ}$ $106^{\circ}, n^{\circ} 3$ do CPI (17) que remete para o Código das Expropriações). Neste caso, e como assinala este ilustre Mestre de Coimbra, operar-se-ia uma extinção do direito de patente na esfera jurídica do seu titular.

Mas este é um passo que, obviamente, ninguém quer dar, nem assumir publicamente, embora estando previsto na nossa lei. Como relembra António Magalhães Cardoso (51), em declarações ao Jornal de Negócios, de 11 de março de 2021, isso poderia implicar um sem- 
número de processos judiciais para se impedir, na prática, tal decisão, incluindo medidas cautelares, ações criminais, sem esquecer o volume de indemnizações a pagar ao titular das patentes em causa.

Talvez que a melhor resposta esteja, afinal, nas posições moderadas de Remédio Marques (13) e Michel Vivant (1), no sentido de que os direitos de patente são ainda muito importantes para manter os estímulos à pesquisa e desenvolvimento de novas substâncias químicas ou matérias biológicas com propriedades terapêuticas (ou de diagnóstico), sem prejuízo de uma maior ponderação na concessão e na utilização de patentes cujo escopo seja menos inventivo ou que não se destinem a produtos estruturalmente novos. A patente tem uma utilização legítima, consagrada nas leis, o titular da patente pode proibir a sua utilização não autorizada, mas, também é verdade que, como todo o direito, deve compreender-se através das suas finalidades.

Contudo, não são os seus usos ilegítimos ou abusivos que, como parte, se podem tomar pelo todo, e não será por isso que a patente deva ser, sob estas considerações, sistematicamente condenada. O objeto específico da patente é, não o esqueçamos, o de assegurar ao seu titular, a fim de recompensar o esforço criador de inventor, o direito exclusivo de utilizar uma invenção no fabrico e na colocação em circulação de produtos industriais, seja por si, seja pelo destinatário de uma licença.

Retomando as palavras de Vivant (1), há, nestes debates, verdades e falsidades, há simplificações que merecem resposta e análise, ou que merecem ser consideradas e há, também, desvirtuamento de direitos que não são conformes à sua matriz inicial, sem descurar os equilíbrios que cumpre prosseguir, como vimos.

Mas, mais importante do que estas discussões académicas, cumpre assinalar que esta saga, muito longe do seu fim, tem nesta etapa da vacinação, em resposta ao horror da pandemia, a beleza do triunfo da Ciência e dos investigadores. Estes, muitas vezes sozinhos na sua perseverança, criaram as condições para permitir à Humanidade sonhar com um regresso a um mundo que já tivemos.

A História não é só estrutural, quantificações, controvérsia, cinismo, agendas escondidas, confrontos ideológicos, é, também, a fabulosa aventura de investigadores e empreendedores que vieram de mundos bem diferentes, muitas vezes sem os meios de que gozam a União Europeia e os EUA.

Jamais esqueceremos os nomes deles: Drew Weissman, Katalin Kirko, Derrick Rossi, Stéphane Bencel, Ugur Sahin, Ozlem Tureci, Anthony Fauci... 


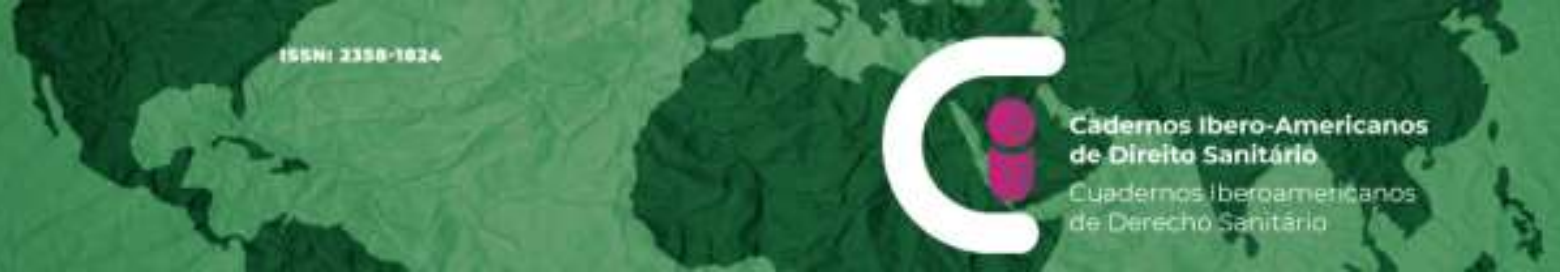

Disponível em: https://www.publico.pt/2021/02/07/opiniao/noticia/dinheiros-publicosvacinas-privadas-razoes-producao-contagotas-1949565

23. Soeiro J. Vacinas, atrasos e patentes: a bolsa ou a vida? Jornal Expresso [internet]. 12 fev. 2021 [citado em 3 maio 2021]. Disponível em: https://expresso.pt/opiniao/2021-02-12Vacinas-atrasos-e-patentes-a-bolsa-ou-a-vida-

24. Roque MP. Façam pouco barulho que o Presidente está a dormir. Jornal Público [internet]. 16 fev. 2021 [citado em 3 maio 2021]. Disponível em:

https://www.publico.pt/2021/02/16/opiniao/noticia/facam-barulho-presidente-dormir$\underline{1950848}$

25. Gusmão J. Vacina Covid: quando as patentes só empatam. Jornal Expresso [internet]. 25 fev. 2021 [citado em 3 maio 2021] Disponível em: https://expresso.pt/opiniao/2021-0225-Vacina-Covid-quando-as-patentes-so-empatam

26. Maia C. As vacinas e o espantalho das patentes. Jornal Expresso [internet].16 fev. 2021 [citado em 3 maio 2021]. Disponível em: https://expresso.pt/opiniao/2021-02-16-Asvacinas-e-o-espantalho-das-patentes

27. Alves IM. Capitalismo vs. humanitarismo na luta pela vacina covid-19. Jornal Expresso [internet]. 26 fev. 2021 [citado em 3 maio 2021]. Disponível em:

https://expresso.pt/opiniao/2021-01-26-Capitalismo-vs.-humanitarismo-na-luta-pela-vacinacovid-19

28. Soares PF. Vacinas: as patentes atrasam a vida. Jornal Público [internet].12 mar. 2021 [citado em 3 maio 2021]. Disponível em:

https://www.publico.pt/2021/03/12/politica/opiniao/vacinas-patentes-atrasam-vida-1954089

29. Martins C. Entrevista por António Cotrim: Covid-19. "UE deve utilizar mecanismos para ultrapassar patentes e generalizar vacina", afirma Catarina Martins. Rádio Observador [internet]. 13 mar. 2021 [citado em 3 maio 2021]. Disponível em:

https://observador.pt/2021/02/13/covid-19-ue-deve-utilizar-mecanismos-para-ultrapassarpatentes-e-generalizar-vacina-afirma-catarina-martins/

30. Jornal de Negócios. 1 fev. 2021.

31. Sousa J. Declarações públicas num comício em Alverca: Jerónimo de Sousa critica "vacinação a conta-gotas" e submissão a grandes laboratórios, Correio da Manhã [internet]. 14 mar. 2021 [citado em 3 maio 2021]. Disponível em:

https://www.cmjornal.pt/politica/detalhe/jeronimo-de-sousa-critica-vacinacao-a-conta-gotase-submissao-a-grandes-laboratorios?ref=Mais\%20Sobre BlocoMaisSobre

32. Roussel F. Citado por Bazat JM. Vaccins : «Est-il injuste que les laboratoires qui ont pris le risque de suivre la piste de l'ADN messager en récoltent les fruits ?» Le Monde 


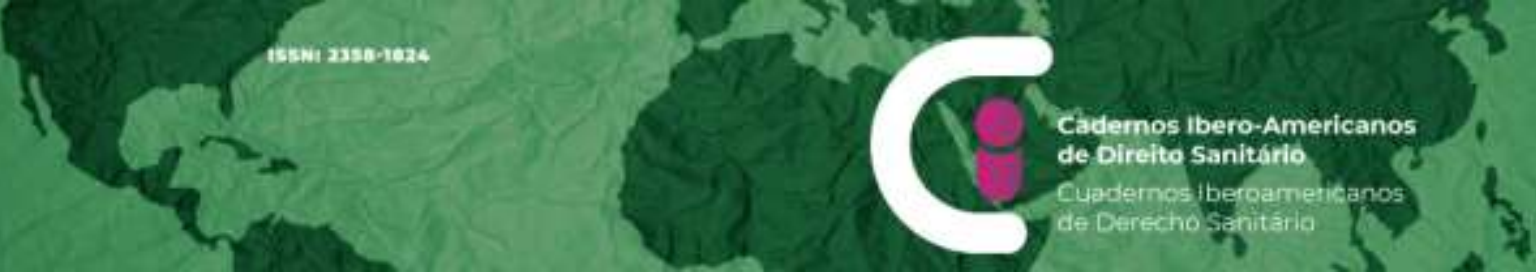

[internet]. 8 fev. 2021 [citado em 3 maio 2021]. Dlsponível em :

https://www.lemonde.fr/economie/article/2021/02/08/vaccins-anti-covid-est-il-injuste-que-

les-laboratoires-qui-ont-pris-le-risque-de-suivre-la-piste-de-l-arn-messager-en-recoltent-lesfruits 6069189 3234.html

33. Gomes A. Nada é agora mais vital para Humanidade. E \#UE está a falhar-nos. Por vossa inacção @vonderleyen @antoniocostapm @2021PortugalEU. Abram patentes JÁ! \#Vacina \#covid ñ é produto de mercado, é Bem Público Universal! Salvem VIDAS!

[Twitter]. 13 mar. 2021 [citado em 3 maio 2021]. Disponível em:

https://twitter.com/AnaMartinsGomes/status/1370706084952936458?s=19\&fbclid=IwAR3

KmLLebIXIFPjrbPUcGmNOgA6c8mqwGiGSOqAktVE6pfala8DnkAHg2o

34. Barroso D. Durão Barroso: farmacêuticas devem "comprometer-se a ajudar a acabar com a pandemia" em vez de ganhar mais dinheiro. Jornal Expresso [internet]. 3 mar. 2021 [citado em 3 maio 2021]. Disponível em: https://expresso.pt/coronavirus/2021-03-03-DuraoBarroso-farmaceuticas-devem-comprometer-se-a-ajudar-a-acabar-com-a-pandemia-emvez-de-ganhar-mais-dinheiro

35. Moura Vicente D. Repensar a propriedade intelectual no contexto da crise mundial. Revista de Direito Intelectual. N²; 2020.

36. Gaviria M, Kilic B. mRNA- 1273 Vaccine Patent (landscape for NIH-moderna Vaccine). Public Citizen. 16 nov. 2020 [citado em 3 maio 2021]. Disponível em:

https://www.citizen.org/article/modernas-mrna-1273-vaccine-patent-landscape/

37. Lexology [internet]. Pfizer's covid vaccine found $90 \%$ effective, but raises IP questions. 9 nov. 2020 [citado em 3 maio 2021]. Disponível em:

https://www.lexology.com/library/detail.aspx?g=600d8fb8-03f3-4a68-87e5-cf339e8fc77b

38. Archer L. Vinte e cinco anos de Genética Molecular. Memórias da Academia das Ciências. (separata). Classe de Ciências. Tomo XXX. Lisboa; 1989.

39. Isaacson W. The Race To Save the World. Revista Time. 18-25 jan. 2021.

Santos G, Tourbe C. Comment l'ARN va changer nos vies. Le Point [internet]. 27 jan. 2021 [citado em 3 maio 2021]. Disponível em: https://www.lepoint.fr/sciences-nature/comment-larn-va-changer-nos-vies-27-01-2021-2411573 1924.php\#xtmc=comment-l-arn-va-changer$\underline{\text { nos-vies \&xtnp }=1 \& x t c r=1}$

40. Hecketsweiler C, Herzberg N. Covid 19: la saga du vaccin à ARN messager désormais dans le sprint final. Le Monde [internet]. 30 dez. 2020 [citado em 3 maio 2021]. Disponível em: https://www.lemonde.fr/sciences/article/2020/11/30/covid-19-la-saga-du-vaccin-a-arnmessager-dans-le-sprint-final 6061695 1650684.html

41. Kariko K. Entrevista por Gwendoline Dos Santos, Guillaume Grallet et Caroline Tourbe : Covid: " Je crois que d'ici à cet été nous aurons vaincu le virus ». Le Point [internet]. 29 


\section{Como citar este artigo}

Lopes Rocha M. O princípio da partilha de saberes científicos vs. propriedade intelectual: a propósito das patentes farmacêuticas no contexto da pandemia de COVID-19. Cadernos Ibero-Americanos de Direito Sanitário. 2021 jul./set.;10(3):144-171.

https://doi.org/10.17566/ciads.v10i3.801 